\title{
Clinical characteristics and public health management of invasive meningococcal group W disease in the East Midlands region of England, United Kingdom, 2011 to 2013
}

J Bethea ${ }^{1}$, S Makki 2 , S Gray ${ }^{3}$, V MacGregor 2 , S Ladhani 4

1. Centre for Medicine, Department of Health Sciences, College of Medicine, Biological Sciences and Psychology, The University of Leicester, Leicester, United Kingdom

2. Public Health England East Midlands, Nottingham, United Kingdom

3. Public Health England, Manchester, United Kingdom

4. Public Health England Colindale, London, United Kingdom

Correspondence: Jane Bethea (Jb518@le.ac.uk)

In England and Wales, meningococcal disease caused by group $\mathrm{W}$ has historically been associated with outbreaks of disease among travellers to high-risk countries. Following a large outbreak associated with travel to the Hajj in 2000, the number of cases declined and, in 2008, only 19 laboratory-confirmed cases were identified nationally. In 2013, in the East Midlands region of England, eight cases of meningococcal disease caused by this serogroup were recorded, compared with six from 2011 to 2012. To explore this further, data for all cases with a date of onset between 1 January 2011 and 31 December 2013 were collected. Data collected included geographical location, clinical presentation and outcome. Fourteen cases were identified; two died as a result of their illness and two developed long-term health problems. No commonality in terms of geographical location, shared space or activities was identified, suggesting that group $\mathbf{W}$ is circulating endemically with local transmission. Clinical presentation was variable. Half presented with symptoms not typical of a classical meningococcal disease, including two cases of cellulitis, which may have implications for clinicians, in terms of timely identification and treatment, and public health specialists, for offering timely antibiotic chemoprophylaxis to close contacts.

\section{Introduction}

There are 13 Neisseria meningitidis capsular groups known to cause invasive meningococcal disease (IMD); in England and Wales, around $80 \%$ of cases are caused by capsular group B (MenB) [1]. Meningococcal group W (MenW) has historically been responsible for only a small proportion of disease in England and Wales. In 2000, however, there was a major international outbreak of meningococcal disease caused by group $W$ (type 2a subtype P1.2, P1.5) associated with pilgrims attending the Hajj. Previously, this strain had only rarely been isolated in European countries [2]. In just over four months in 2000, 90 cases were reported from nine European counties, with 42 of these in the United Kingdom (UK) and 24 in France [2].

Following the Hajj-related outbreak, MenW became an increasingly common cause of IMD in different parts of the world. In Gauteng Province in South Africa (which includes the cities of Pretoria and Johannesberg), for example, MenW is now considered endemic, accounting for $75 \%$ of cases in 2005 compared with $7 \%$ in 2000 [3]. In 2002, in Burkina Faso, 13,000 suspected cases were recorded, with the highest attack rates seen in infants aged one year and under $(1,092 / 100,000)$ [4]. Other sub-Saharan countries have similarly reported an increase in MenW disease, also in young children, following the successful implementation of the MenA conjugate vaccine $[5,6]$.

Following the introduction of mandatory vaccination for Hajj pilgrims, the number of MenW cases in England and Wales declined rapidly, from 5.2\% (127/2,448) laboratory-confirmed IMD cases in the 2000/01 epidemiological year to1.8\% $(21 / 1,164)$ in $2008 / 09$. Since 2009/10, however, MenW cases have increased yearon-year, with 98 cases confirmed in 2013/14, accounting for $15 \%$ of 664 IMD cases [7].

In 2013, health protection teams working in the East Midlands area of England were notified of eight MenW cases, including six cases notified within a three-month period (September to November 2013). We therefore undertook detailed analysis of all laboratory-confirmed 
TABLE 1

Clinical presentation, sub-type, outcome and underlying health conditions by age group for invasive meningococcal group $\mathrm{W}$ disease cases observed in the East Midlands region of England, United Kingdom, 2011-2013 ( N = 14)

\begin{tabular}{|c|c|c|c|c|}
\hline \multirow[b]{2}{*}{ Clinical characteristic } & \multicolumn{3}{|c|}{ Number of cases by age category } & \multirow[b]{2}{*}{ Total $(\mathrm{N}=14)$} \\
\hline & $\begin{array}{c}0-5 \text { years } \\
(n=3)\end{array}$ & $\begin{array}{c}6-50 \text { years } \\
(\mathrm{n}=5)\end{array}$ & $\begin{array}{c}>50 \text { years } \\
(n=6)\end{array}$ & \\
\hline \multicolumn{5}{|l|}{ Recorded symptoms on admission } \\
\hline Fever & 2 & 1 & 2 & 5 \\
\hline \multicolumn{5}{|l|}{ Respiratory } \\
\hline Runny nose & 2 & 0 & 1 & 3 \\
\hline Breathing difficulties & 1 & o & 1 & 2 \\
\hline Chest pain & 0 & 1 & 1 & 2 \\
\hline \multicolumn{5}{|l|}{ Gastrointestinal symptoms } \\
\hline Diarrhoea & 1 & 1 & 1 & 3 \\
\hline Vomiting & 0 & 1 & 1 & 2 \\
\hline Abdominal pain & 0 & 1 & 0 & 1 \\
\hline \multicolumn{5}{|l|}{ Skin and soft tissue } \\
\hline Non-blanching rash & 1 & o & 1 & 2 \\
\hline Cellulitis & 0 & 1 & 1 & 2 \\
\hline \multicolumn{5}{|l|}{ Bone and joint } \\
\hline Joint pain & o & o & 1 & 1 \\
\hline Septic joint & 1 & 0 & 0 & 1 \\
\hline \multicolumn{5}{|l|}{ Neurological } \\
\hline Headache & o & 0 & 1 & 1 \\
\hline \multicolumn{5}{|l|}{ Non-specific } \\
\hline Tiredness & 0 & 0 & 1 & 1 \\
\hline \multicolumn{5}{|l|}{ Underlying health conditions } \\
\hline Immunocompromised & o & 1 & o & 1 \\
\hline Diabetes & 0 & 0 & 1 & 1 \\
\hline \multicolumn{5}{|l|}{ Outcome } \\
\hline Death & 1 & 0 & 1 & 2 \\
\hline Serious long-term consequences & o & $1^{\mathrm{a}}$ & o & 1 \\
\hline Other long-term consequences & o & $1^{\mathrm{b}}$ & 0 & 1 \\
\hline No complications & 2 & 3 & 5 & 10 \\
\hline
\end{tabular}

a Locked-in syndrome.

${ }^{\mathrm{b}}$ Bilateral hearing loss.

MenW cases in the East Midlands over three calendar years (2011-2013) to identify any epidemiological links between the cases and to describe key features, including patient demographics, travel history, co-morbidities, clinical presentation, complications at hospital discharge and outcome.

\section{Methods}

All laboratory-confirmed IMD cases reported to Public Health England (PHE) between 1 January 2011 and 31 December 2013 in the East Midlands region of England were identified through a systematic search of HPZone, a national computerised system used to record all health protection activity undertaken by Public Health England. It is designed to assist with public health management of individual cases and to facilitate outbreak and incident management. Data for one area of the East Midlands (Northamptonshire) were only available up to April 2013 as changes in geographical boundaries meant this area became the responsibility of another regional health protection team. Queries were developed to identify any HPZone cases with ' $W$ ' and 'meningococcal' mentioned in key recording fields. The confirmed meningococcal cases in the period of interest were also hand-searched. For validation purposes, cases occurring in 2013 were checked against data held by PHE's national Meningococcal Reference Unit (MRU) in Manchester. All identified cases were included in the MRU dataset and no further eligible cases were found. Submission of invasive meningococcal isolates to the MRU allows both phenotypic and comprehensive genotypic characterisation for local and national surveillance, including identification of closely-related strains in clusters and outbreaks. Since July 2010, all clinical isolates have been subjected to whole genome sequencing [8]. The MRU also provides a free national PCR-testing service for National Health Service (NHS) for non-culture confirmation of IMD in 
suspected cases and identification of the responsible meningococcal capsular group. Information was collated on method of case identification, the phenotype (serotype and sero-subtype) and the multilocus sequence type (MLST) clonal complex (CC) as described in the Meningitis Research Foundation (MRF) Meningococcus Genome Library MGL, (http://www. meningitis.org/research/genome).

Data from identified MenW cases were extracted using a pre-defined questionnaire and entered into Microsoft Excel for descriptive analysis. Data collected included demographic information, risk factors, activity in the seven days before onset, clinical presentation and outcome. Date of onset, date of hospitalisation and date of notification to PHE were also collected and used to assess any differences in time to notification for MenW cases with typical and atypical clinical presentations. The i2 Analyst's Notebook software package was also used to provide a visual representation of each case and to facilitate the identification of any commonality between cases.

\section{Results}

The HPZone search identified 14 laboratory-confirmed MenW cases in the East Midlands region during 201113. Just over half of cases were female $(n=8,57.1 \%)$ and only one case had a recorded ethnicity that was not White British. The median age of cases was 47 years (range: 3 months to 87 years) and half the cases were diagnosed in $\geq 45$ year-olds. Three cases were in infants (aged 11 year), including one who died as a result of the infection. All cases were assessed for commonality in relation to date of onset, geographical location and contact history in the seven days before onset. There were six cases in 2 years: three in 2011 and three in 2012, and eight cases in 2013, including six in the period from 1 September 2013 to 30 November 2013. No commonality between these cases could be identified. In terms of activity in the seven days before IMD onset, three had a travel history recorded: one within the UK and two abroad, but not to countries at highrisk for MenW (for example, Sub-Saharan Africa). From the information available, none of the cases had been in contact with anyone who had recently travelled to a high-risk country.

The age distribution, clinical presentation, co-morbidities and outcomes are summarised in Table 1.

The most commonly recorded symptom at admission was fever, followed by coryzal symptoms and diarrhoea. Of the 14 cases, seven were considered to have an atypical presentation. One case presented with abdominal pain and fever and was initially diagnosed with appendicitis, while another case presented with diarrhoea and vomiting only. Two other cases presented with cellulitis and another with a septic joint. The overall median time from hospitalisation to reporting the case to PHE was two days (interquartile range: 2.5 days). For cases with atypical presentation the median was three days (interquartile range: 5 days) compared with 0.5 days (interquartile range: 1.75 days) for those with typical presentation.

Three cases had a known underlying health condition; one was immunocompromised, another had diabetes and the third had borderline myeloma but was not immunocompromised. Two patients died as a result of their illness, an infant and an older adult aged $>85$ years. One case also developed locked-in syndrome after reaching hospital in a critical condition and another developed bilateral hearing loss following MenW meningitis.

Thirteen cases were confirmed by culture and one by PCR only (Table 2).

All 13 meningococcal isolates underwent serological phenotyping and $10(76.9 \%)$ were serotype $2 \mathrm{a}$, of which seven $(53.8 \%)$ were sero-subtypes $\mathrm{P}_{1.5}$ or $\mathrm{P}_{1} .2$ (Table 2).

MLST CC was available for all 13 culture positive cases and of these 10 belonged to clonal complex cc11, thereby confirming the strong association between serotype $2 \mathrm{a}$ and cc11. All seven case isolates phenotyped as sero-subtype $\mathrm{P}_{1.5}$ and $\mathrm{P}_{1.2}$ were confirmed as porAVR1 5 and porAVR2 2. The 10 cc11 case isolates were subjected to whole genome sequencing as part of enhanced national surveillance and belonged to the South American/UK strain recently identified and reported by PHE MRU [8]. The PCR-only case was determined to be porAVR1 5 and porAVR 22 by specific gene sequencing.

\section{Discussion}

The recent increase in MenW cases diagnosed in the East Midlands mirrors the national year-on-year rise in laboratory-confirmed MenW cases since 2009 [7]. Detailed analysis of the 14 identified cases found no clear epidemiological link between the cases, but highlighted the severe course of illness with unfavourable outcomes across all age groups. The lack of overseas travel to high-risk countries and a lack of shared activities or space, suggests that this strain is circulating in our region with local transmission. Furthermore, molecular characterisation and whole genome sequencing of clinical isolates found a single strain to be responsible for 10 of the 13 cases [8]. Because of the small number of cases, it is not possible to determine whether this particular strain was associated with more severe disease outcomes, in terms of clinical presentation, long-term complications or death. However, our findings do fit with existing evidence that, when compared with the more common MenB cases, MenW cases were more likely to have atypical clinical presentations [7]. Atypical clinical presentations have important implications in terms of delays in diagnosis and notification to health protection teams, leading to delays in treatment, contact tracing and timely administration of antibiotic 
TABLE 2

Phenotype and genotype of culture for all 14 cases observed in the East Midlands region of England, United Kingdom, 2011-2013

\begin{tabular}{|c|c|c|c|c|c|c|}
\hline \multirow{2}{*}{ Case number } & \multirow{2}{*}{$\begin{array}{l}\text { Age category } \\
\text { (years old) }\end{array}$} & \multirow{2}{*}{ Phenotype } & \multicolumn{4}{|c|}{ Sequence typing from whole genome sequencing } \\
\hline & & & porAVR1 & porAVR2 & Sequence type & Clonal complex \\
\hline 1 & $0-5$ & $W: 2 a: P_{1} .5,2$ & 5 & 2 & 11 & 11 \\
\hline 2 & $0-5$ & W (PCR only) & 5 & 2 & NA & NA \\
\hline 3 & $0-5$ & W:NT:P1.5 & $5-1$ & $10-4$ & 184 & 22 \\
\hline 4 & $6-50$ & $W: 2 a: P 1.5,2$ & 5 & 2 & 11 & 11 \\
\hline 5 & $6-50$ & $W: 2 a: P_{1.5,2}$ & 5 & 2 & 11 & 11 \\
\hline 6 & $6-50$ & W:2a:P1.2 & 5 & 2 & 11 & 11 \\
\hline 7 & $6-50$ & $W: 2 a: P_{1.5,2}$ & 5 & 2 & 11 & 11 \\
\hline 8 & $6-50$ & W:2a:NT & 5 & 2 & 11 & 11 \\
\hline 9 & $>50$ & W:NT:P1.3 & $18-1$ & 3 & 1281 & 22 \\
\hline 10 & $>50$ & $W: 2 a: P_{1} \cdot 5,2^{1}$ & 5 & 2 & 11 & 11 \\
\hline 11 & $>50$ & W:2a:P1.14 & $7^{-2}$ & 14 & 11 & 11 \\
\hline 12 & $>50$ & $W: 2 a: P 1.5,2$ & 5 & 2 & 10651 & 11 \\
\hline 13 & $>50$ & $W: 2 a: P_{1.5}, 2$ & 5 & 2 & 11 & 11 \\
\hline 14 & $>50$ & W:NT:NT & 22 & 14 & 184 & 22 \\
\hline
\end{tabular}

NA: not available.

chemoprophylaxis to close contacts for prevention of secondary IMD cases.

Internationally, policies vary but vaccination is generally restricted to high-risk groups or as part of outbreak management. Exceptions include the United States where all 11-18 year olds are offered the conjugate quadrivalent MenACWY vaccine [9]. In August 2015, and in response to rapid expansion of the endemic hyper-virulent MenW cc11 strain, a MenACWY catch-up programme was introduced in the UK for young people aged $14-18$ and those aged less than 25 years and attending university for the first time [10]. In England and Wales, vaccination against MenW is also recommended for travellers to MenW endemic countries, for at-risk individuals with conditions such as asplenia, hyposplenia and complement deficiency, and also for close contacts of patients with IMD caused by this serogroup [1].

It is important that clinicians are aware of the changing IMD epidemiology and the unique characteristics of MenW that differentiate this capsular group from the classical presentations associated with MenB or MenC. IMD generally can be difficult to diagnose because symptoms are often similar to a viral illness, especially in the early stages of illness (e.g. fever, headache, runny nose). Classical symptoms associated with IMD such as the non-blanching rash, neck stiffness and impaired consciousness tend to present later, by which time the patient is already seriously ill and more likely to have an adverse outcome [11]. In our cohort, information on clinical presentation was derived from information recorded when the patient arrived at the hospital emergency department. Notably, more than half of the patients did not have any of the classical symptoms of meningococcal disease. This is consistent with published reports confirming that patients with MenW are more likely to develop non-meningeal manifestations such as arthritis, pericarditis and pneumonia [12-14]. In France, analysis of all cases of meningococcal disease between 1999 and 2002 found that MenW was significantly more likely than other capsular groups to be associated with meningococcal arthritis and meningococcal pneumonia [12]. Two patients in our cohort presented with cellulitis, which is a rare manifestation of IMD, previously only reported in individual case reports or small case studies and more often associated with MenY or MenB $[15,16]$. IMD presentation with common gastrointestinal symptoms such as diarrhoea and vomiting has also been reported in the literature. In one study, for example, 24 patients were erroneously hospitalised for gastrointestinal symptoms (with two having appendectomy) and were subsequently found to have meningococcal disease [12]. The age distribution of MenW cases is also different to the more common MenB or MenC cases. In our cohort, for example, half the cases were diagnosed in older adults, who would generally not be considered to have IMD, especially if they develop atypical clinical manifestations such as pneumonia or septic arthritis.

An important consequence of the unusual clinical presentation of MenW disease is that a diagnosis of IMD is often not considered until $N$. meningitidis is isolated from sterile-site cultures (blood, cerebrospinal fluid (CSF), joint), which on average takes 24-72 hours. Confirmation of capsular group can take longer because this requires isolate submission to the national reference laboratory. While PCR confirmation of IMD and capsular group may be quicker, it requires the clinician to consider IMD in the differential diagnosis. In 
England and Wales, local hospital laboratories do not offer PCR-testing for meningococcal disease. Therefore, the sterile-site samples (blood/CSF/joint) have to be submitted to the national reference laboratory (MRU), which offers a free national PCR-testing service. This is less likely to occur if patients have non-specific and/or atypical clinical presentations, which is more likely to occur with MenW. The submission of all meningococcal isolates to the $\mathrm{MRU}$, irrespective of PCR investigations, is essential for continued national surveillance, particularly in light of the two new meningococcal immunisation programmes introduced in 2015 [17].

The analysis presented here is limited by the small number of cases, but we have identified a clear increase in MenW cases locally, which is consistent with national trends. The recent emergence of a single strain responsible for most of the recent MenW cases and the lack of a travel history in most patients suggest that this strain is endemic and could lead to further increases in MenW cases. Moreover, although HPZone records limited clinical data, we found that a considerable proportion of cases did not have the classical symptoms of IMD and, as a result, diagnosis and treatment (as well as public health notification and antibiotic chemoprophylaxis for close contacts) may be delayed. Clinicians should, therefore, be aware of the national increase in MenW cases, the atypical clinical presentations associated with MenW disease and the importance of early notification of confirmed cases to local health protection teams to ensure timely chemoprophylaxis and vaccination are offered to close contacts.

\section{Conflict of interest}

None declared.

\section{Authors' contributions}

Jane Bethea designed the study, completed data collection and analysis and wrote the first full draft of the article. Shamez Ladhani provided advice on overall approach to the study and made a significant contribution to the writing of the final manuscript. Sophia Makki provided advice on the initial development of the study, on data collection and interpretation and commented on the final draft of the article. Steve Gray provided national data for validation purposes, data on method of identification and type/subtype and also commented on all drafts of the article. Vanessa MacGregor provided advice on interpretation of the data, data collection and commented on the final draft of the article.

\section{References}

1. Ladhani SN, Flood JS, Ramsay ME, Campbell H, Gray SJ, Kaczmarski EB, et al. Invasive meningococcalhttp://www.ncbi. nlm.nih.gov/pubmed/22429756disease in England and Wales: implications for the introduction of new vaccines. Vaccine. 2012;30(24):3710-6.

2. Aguilera JF, Perrocheau A, Meffre C, Hahné S, W135 Working Group. Outbreak of serogroup W135 meningococcal disease after the Hajj pilgrimage, Europe, 2000.Emerg Infect Dis. 2002;8(8):761-7. DOI: 10.3201/eido808.010422 PMID: 12141959

3. von Gottberg A, du Plessis M, Cohen C, Prentice E, Schrag $S$, de Gouveia L, et al. , Group for Enteric, Respiratory and Meningeal Disease Surveillance in South Africa. Emergence of endemic serogroup W135 meningococcal disease associated with a high mortality rate in South Africa.Clin Infect Dis. 2008;46(3):377-86. DOI: 10.1086/525260 PMID: 18181736

4. Nathan N, Rose AMC, Legros D, Tiendrebeogo SRM, Bachy C, Bjørløw E, et al. Meningitis serogroup W135 outbreak, Burkina Faso, 2002. Emerg Infect Dis. 2007;13(6):920-3. DOI: 10.3201/ eid1306.060940 PMID: 17553237

5. Collard JM, Issaka B, Zaneidou M, Hugonnet S, Nicolas P, Taha MK, et al. Epidemiological changes in meningococcal meningitis in Niger from 2008 to 2011 and the impact of vaccination. BMC Infect Dis. 2013;13(1):576. DOI: 10.1186/14712334-13-576 PMID: 24313998

6. Hossain MJ, Roca A, Mackenzie GA, Jasseh M, Hossain MI, Muhammad S, et al. Serogroup W135 meningococcal disease, The Gambia, 2012. Emerg Infect Dis. 2013;19(9):1507-10. DOI: 10.3201/eid1909.130077 PMID: 23965435

7. Ladhani SN, Beebeejaun K, Lucidarme J, Campbell H, Gray S, Kaczmarski E, et al. Increase in Endemic Neisseria meningitidis Capsular Group W Sequence Type 11 Complex Associated With Severe Invasive Disease in England and Wales.http://www. ncbi.nlm.nih.gov/pubmed/25389259Clin Infect Dis. 2014 Nov 10. pii: ciu881.

8. Lucidarme J, Hill DM, Bratcher HB, Gray SJ, du Plessis M, Tsang RS, et al. Genomic resolution of an aggressive, widespread, diverse and expanding meningococcal serogroup B, C and W lineage. J Infect. 2015;71(5):544-52. DOI: 10.1016/j. jinf.2015.07.007 PMID: 26226598

9. Harrison LH, Pelton SI, Wilder-Smith A, Holst J, Safadi MA, Vazquez JA, et al. The Global Meningococcal Initiative: recommendations for reducing the global burden of meningococcal disease. Vaccine. 2011;29(18):3363-71. DOI: 10.1016/j.vaccine.2011.02.058 PMID: 21376800

10. Public Health England (PHE). Meningococcal: the green book, chapter 22. London: PHE; March 2013. Available from: https://www.gov.uk/government/publications/ meningococcal-the-green-book-chapter-22

11. Thompson MJ, Ninis N, Perera R, Mayon-White R, Phillips C, Bailey $L$, et al. Clinical recognition of meningococcal disease in children and adolescents. Lancet. 2006;367(9508):397-403 DOI: 10.1016/S0140-6736(06)67932-4 PMID: 16458763

12. Vienne P, Ducos-Galand M, Guiyoule A, Pires R, Giorgini D, Taha $M-K$, et al. The role of particular strains of Neisseria meningitidis in meningococcal arthritis, pericarditis, and pneumonia. Clin Infect Dis. 2003;37(12):1639-42. DOI: 10.1086/379719 PMID: 14689345

13. Wang JL, Liu DP, Yen JJ, Yu CJ, Liu HC, Lin CY, et al. Clinical features and outcome of sporadic serogroup W135 disease Taiwan. BMC Infect Dis. 2006;6(1):7. DOI: 10.1186/1471-2334-67 PMID: 16420709

14. Faye A, Mariani-Kurkdjian P, Taha M-K, Angoulvant F, Antonios $M$, Aubertin G, et al. Clinical features and outcome of pediatric Neisseria meningitidis serogroup W135 infection: a report of 5 cases. Clin Infect Dis. 2004;38(11):1635-7. DOI: 10.1086/421022 PMID: 15156454

15. Cartolano GL, Barbier C, Arnoult L, Simon D, Ricome JL, Hayon J. Fatal acute cellulitis due to Neisseria meningitidis.J Clin Microbiol. 2003;41(8):3996-7. DOI: 10.1128/JCM.41.8.39963997.2003 PMID: 12904440

16. Porras MC, Martínez VC, Ruiz IM, Encinas PM, Fernandez MT, García J, et al. Miguel Carrascosa Porras, Victor Ca. Acute cellulitis: an unusual manifestation of meningococcal disease.Scand J Infect Dis. 2001;33(1):56-9. DOI: 10.1080/003655401750064086 PMID: 11234980

17. Public Health England (PHE). National enhanced surveillance of vaccination programmes targeting invasive meningococcal disease in England. 2014. [Accessed 14 Jun 2016]. Available from: https://www.gov.uk/government/ uploads/system/uploads/attachment_data/file/484661/ MeningoEnhancedSurveillancePlan_Final_Dec15.pdf

\section{License and copyright}

This is an open-access article distributed under the terms of the Creative Commons Attribution (CC BY 4.0) Licence. You may share and adapt the material, but must give appropriate credit to the source, provide a link to the licence, and indicate if changes were made.

This article is copyright of the authors, 2016. 